\title{
Homeostasis model assessment: insulin resistance and $\beta$-cell function from fasting plasma glucose and insulin concentrations in man
}

\author{
D. R. Matthews, J.P.Hosker, A. S. Rudenski, B. A. Naylor, D. F. Treacher and R. C. Turner \\ Diabetes Research Laboratories, Radcliffe Infirmary, Oxford, UK
}

\begin{abstract}
Summary. The steady-state basal plasma glucose and insulin concentrations are determined by their interaction in a feedback loop. A computer-solved model has been used to predict the homeostatic concentrations which arise from varying degrees of $\beta$-cell deficiency and insulin resistance. Comparison of a patient's fasting values with the model's predictions allows a quantitative assessment of the contributions of insulin resistance and deficient $\beta$-cell function to the fasting hyperglycaemia (homeostasis model assessment, HOMA). The accuracy and precision of the estimate have been determined by comparison with independent measures of insulin resistance and $\beta$-cell function using hyperglycaemic and euglycaemic clamps and an intravenous glucose tolerance test. The estimate of insulin resistance obtained by homeostasis model assessment correlated with estimates obtained by use of the euglycaemic clamp $\left(\mathrm{R}_{\mathrm{s}}=0.88, p<0.0001\right)$, the fasting insulin concentration $\left(\mathrm{R}_{\mathrm{s}}=0.81, p<0.0001\right)$, and the hyperglycaemic
\end{abstract}

clamp, $\left(R_{s}=0.69, p<0.01\right)$. There was no correlation with any aspect of insulin-receptor binding. The estimate of deficient $\beta$ cell function obtained by homeostasis model assessment correlated with that derived using the hyperglycaemic clamp $\left(\mathrm{R}_{\mathrm{s}}=0.61, p<0.01\right)$ and with the estimate from the intravenous glucose tolerance test $\left(\mathrm{R}_{\mathrm{s}}=0.64, p<0.05\right)$. The low precision of the estimates from the model (coefficients of variation: $31 \%$ for insulin resistance and $32 \%$ for $\beta$-cell deficit) limits its use, but the correlation of the model's estimates with patient data accords with the hypothesis that basal glucose and insulin interactions are largely determined by a simple feed back loop.

Key words: $\beta$-cell function, insulin resistance, mathematical model, intravenous glucose tolerance test, glucose clamp, insulin receptors, Type 2 diabetes, insulin, glucose.
The fasting plasma glucose and insulin concentrations in each normal subject or Type 2 (non-insulin-dependent) diabetic patient are set at a level characteristic for that individual for a given state of nutrition [1,2]. The fasting plasma insulin concentration is largely determined by the glucose concentration [3] and the basal hyperglycaemia in diabetes appears to arise from the feedback loop between the liver and $\beta$-cells, thereby maintaining an effective insulin action in the liver and at the periphery $[1,4]$. The degree of basal hyperglycaemia is thus determined by a combination of $\beta$-cell deficiency and insulin resistance. A mathematical model of the glucose: insulin interactions has been used to indicate the degree to which they combine to give hyperglycaemia with low, normal or raised basal plasma insulin concentrations $[5,6]$. The predictions from the model are in accord with known data in man [5]. A formal test has now been undertaken of the degree to which insulin resistance and deficient $\beta$-cell function can be assessed from a patient's fasting plasma insulin and glucose con- centrations. We term this interpretation of the 'set' of a feedback loop "homeostasis model assessment" (HOMA).

A computer-solved model of insulin: glucose interactions has been used to plot an array of fasting plasma insulin and glucose concentrations that would be expected for varying degrees of $\beta$-cell deficiency and insulin resistance. From the array one can estimate the insulin resistance and deficient $\beta$-cell function which might have been expected to give the fasting plasma glucose and insulin concentrations observed in a patient. These HOMA estimates have been compared with independent estimates of $\beta$-cell function and insulin resistance. The additional estimates of $\beta$-cell function were derived from responses to (1) a hyperglycaemic clamp [7], and (2) an intravenous glucose tolerance test. Insulin resistance was independently assessed using (1) an euglycaemic hyperinsulinaemic clamp [7], (2) an hyperglycaemic clamp, (3) the degree of obesity, (4) the fasting plasma insulin levels alone, and (5) monocyte and erythrocyte 


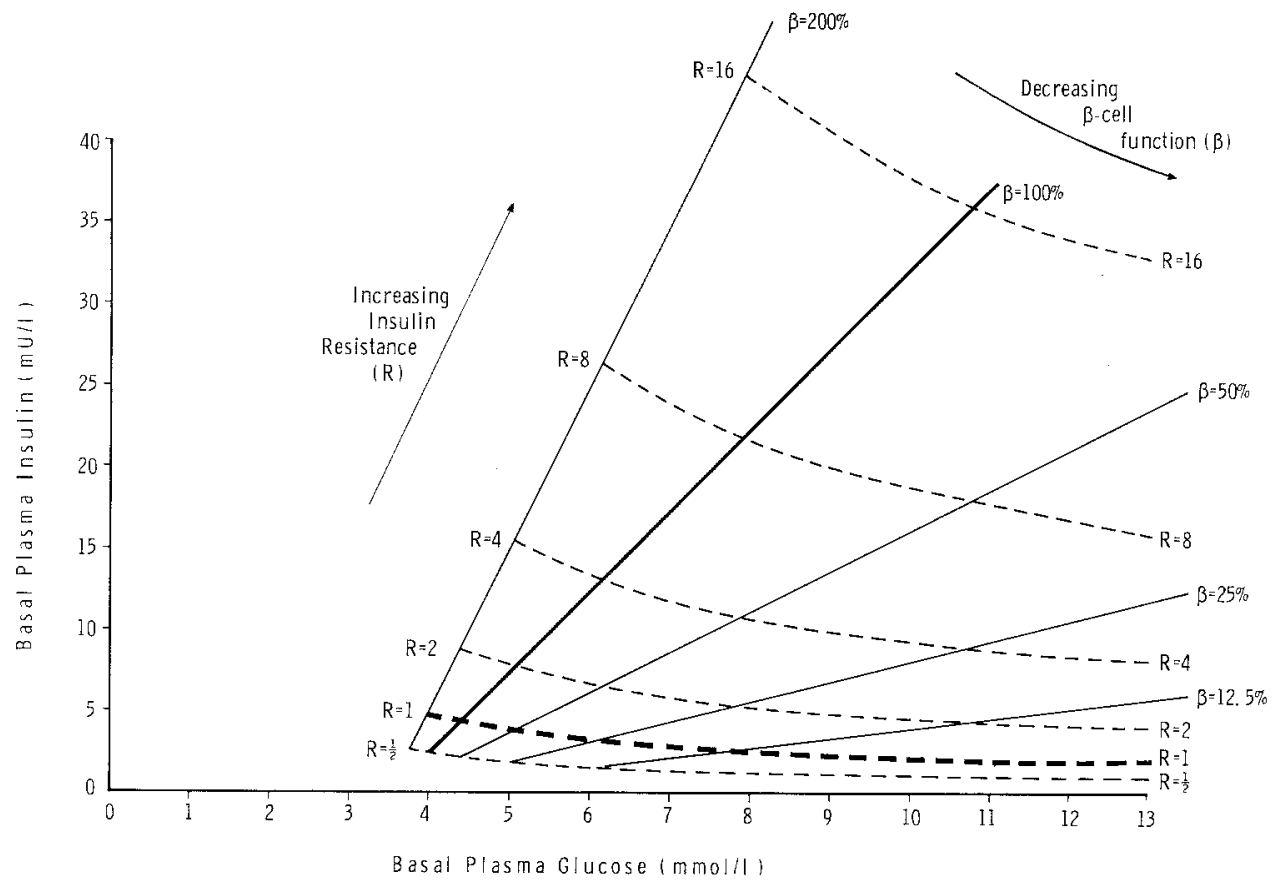

Fig. 1. Basal homeostasis model assessment (HOMA). Computer model predictions for the basal or fasting state in man. The grid shows the model prediction of the steady-state plasma glucose and insulin concentrations for a series of different $\beta$-cell functions $(-)$ and insulin resistance values (-----). For any individual, fasting observations of plasma glucose and insulin may be entered on the grid and the estimated $\beta$-cell function and insulin resistance obtained insulin receptor status [8]. Both insulin resistance and $\beta$ cell function estimates have been compared with those obtained after continuous infusion of glucose with model assessment (CIGMA) [9].

\section{Methods}

\section{Subjects and procedures}

Diabetic subjects satisfied World Health Organisation criteria [10] at the time of presentation, were then treated by diet and, at the time of study, none had glycosuria. The studies were approved by the Oxford Health Authority Ethics Committee and all subjects gave their informed consent.

Homeostasis model analysis (HOMA). The computer model of fasting or basal insulin: glucose interaction has been described previously [5, 6 , 9]. The $\beta$-cell curve is based on near-steady-state C-peptide responses to 2.5 -h hyperglycaemic clamps at plasma glucose concentrations of $7.5,10$ and $15 \mathrm{mmol} / \mathrm{l}$ in six normal subjects aged $40-68$ years [11]. They had a nearly linear glucose: C-peptide dose-response curve with an intercept on the glucose axis of $3.5 \mathrm{mmol} / \mathrm{l}$ (Fig. 1). Five maturity-onset diabetic patients treated by diet alone and with a fasting plasma glucose $5.5-6.5 \mathrm{mmol} / 1$, had a similar intercept with reduced slope. The plasma glucose:insulin response for normal subjects, equivalent to the $\mathrm{C}$-peptide response, is insulin $=5$ (glucose- 3.5 ). With this steady-state measure of $\beta$-cell function, the model allows assessment of the basal, steady state plasma glucose and insulin levels which are appropriate for different degrees of $\beta$-cell dysfunction and insulin resistance (Fig.1). Any combination of insulin resistance and $\beta$-cell deficit provides a unique set of plasma insulin and glucose concentrations. The deficient $\beta$-cell function and insulin resistance can thus be read off this graph or obtained from a numerical array of plasma insulin and glucose concentrations. Assuming that normal-weight normal subjects aged $<35$ years have $100 \% \beta$-cell function, and an insulin resistance of 1 , the values for a patient can be assessed from the insulin and glucose concentrations by the formulae: $\beta$-cell function $(\%)=20 \times$ insulin $/($ glucose- 3.5$)$, and (near approximation) resistance $=$ insulin $/\left(22.5 \mathrm{e}^{- \text {Inglucose }}\right)$.
Comparison of insulin resistance and $\beta$-cell function estimates by $\mathrm{HO}$ $M A$ with estimates from intravenous glucose tolerance test and insulin receptor studies. Six normal male subjects (aged 23-67 years) and six Type 2 diabetic men (aged 46-68 years) were studied on three separate occasions in random order. Their details have been reported elsewhere [9]. On one occasion, they were admitted at $20.00 \mathrm{~h}$ to a metabolic ward, and a double lumen $21 \mathrm{G}$ Teflon catheter (Venflon, Viggo, Helsingborg, Sweden) was placed under local anaesthesia into a distal forearm vein warmed to enhance flow. Heparin was infused through the outer lumen at $1 / 100$ of the blood extraction rate. Blood samples were taken continuously (integrated sampling) [12] from the central lumen by a rotary pump (Watson-Marlow, Bucks, UK) into a fraction collector (Redirac, LKB, Bromma, Sweden), which moved forward each 15 min to collect samples for overnight basal plasma insulin and glucose concentrations in sleeping subjects. At 08.00 hours the next morning, $110 \mathrm{ml}$ of blood were taken for monocyte and erythrocyte insulin-receptor assay. The integrated sampling rate was increased to one fraction per minute, and glucose $(0.2 \mathrm{~g} / \mathrm{kg}$ ideal body weight) [13] was then given over 2 min through a separate cannula in an antecubital vein. The mean plasma insulin concentration between 10 and 30 min after the glucose bolus was used as a measure of $\beta$-cell function. On two other mornings the patients attended hospital for tests. On one a euglycaemic clamp was performed and on the other a CIGMA test was done (vide infra) [9].

Samples taken at $0300-0500 \mathrm{~h}$ were designated 'overnight basal', samples taken between 06.30 and $07.30 \mathrm{~h}$ after the overnight study were designated 'basal', and samples taken when the subject came to the hospital in the morning for either the CIGMA or the clamp were termed 'stressed fasting' [2].

Comparison of insulin resistance measured by HOMA with the estimate by euglycaemic clamp. Twelve normal subjects (aged 23-67 years, $90-142 \%$ ideal body weight), and 11 Type 2 diabetic patients (aged 46-68 years, $100-176 \%$ ideal body weight) were studied as reported previously [9] by the euglycaemic hyperinsulinaemic clamp technique $[9,14]$. Insulin resistance was assessed using the glucose infusion rate over the last $20 \mathrm{~min}$, expressed relative to the median of values $(0.59 \mathrm{~g} / \mathrm{min}$ for a $70 \mathrm{~kg}$ subject $)$ from normal-weight normal subjects which was designated as 1 .

Comparison of insulin resistance and $\beta$-cell function measured by HOMA with CIGMA estimates. The same 12 normal subjects and 11 
Table 1. Clinical features of diabetic subjects in reproducibility study

\begin{tabular}{|c|c|c|c|c|c|c|}
\hline Subject & \multicolumn{3}{|c|}{ At presentation } & \multicolumn{3}{|c|}{ At investigation } \\
\hline 71 & Thirst & 15.2 & 87 & 11 & 5.0 & 82 \\
\hline 52 & Thirst & 14.5 & 77 & 3 & 7.1 & 71 \\
\hline 73 & Dysuria & 8.8 & 107 & 1 & 7.2 & 101 \\
\hline 74 & Nocturia & 17.0 & 81 & 10 & 5.0 & 63 \\
\hline 75 & Incidental & 7.9 & 80 & 3 & 7.6 & 76 \\
\hline 69 & Thirst & 12.8 & 84 & 6 & 6.8 & 82 \\
\hline 76 & Polyuria & 16.0 & 79 & 4 & 5.9 & 82 \\
\hline
\end{tabular}

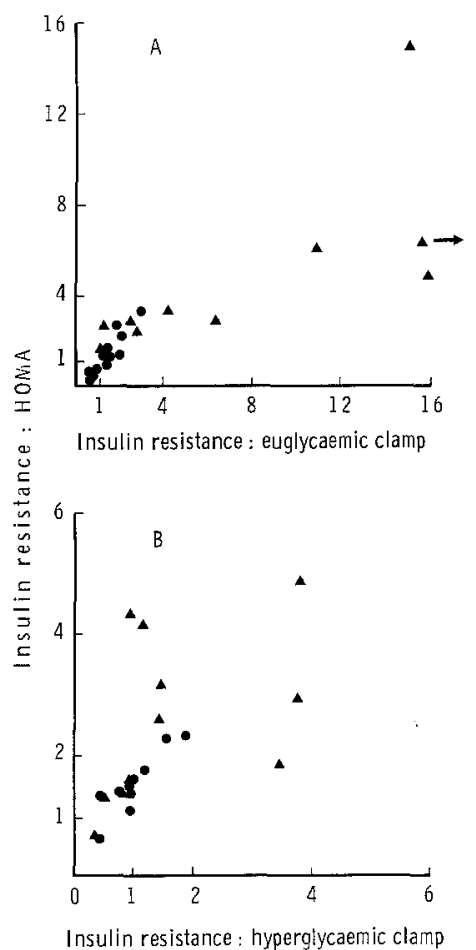

Fig. $2 \mathrm{~A}$ and B. Measures of relative insulin resistance by HOMA compared with those assessed by $\mathbf{A}$ euglycaemic clamp, and $\mathbf{B}$ hyperglycaemic clamp in two separate groups of normal $(\mathbf{0})$ and diabetic A subjects. The insulin resistance values for the clamps have been normalised to unity for the median of normal weight, normal subjects aged $<35$ years [9]

Type 2 diabetic patients came to the hospital fasting on a separate day for a continuous infusion of a $10 \mathrm{~g} / \mathrm{dl}$ solution of glucose at a dose of $5 \mathrm{mg} / \mathrm{kg}$ ideal body weight per min [9]. HOMA was assessed from the 15 min 'stressed fasting' samples before the glucose infusion.

Comparison of $\beta$-cell function and insulin resistance measured by $\mathrm{HO}$ $M A$ and the hyperglycaemic clamp. Ten normal subjects (aged 22-69 years, $90-113 \%$ ideal body weight) and 11 Type 2 diabetic subjects treated by diet alone (aged $40-69$ years, $97-174 \%$ ideal body weight) were studied. Their details have been reported elsewhere [9]. A hyperglycaemic clamp at $10 \mathrm{mmol} / 1$ was performed on patients who came fasting in the morning [7, 14]. $\beta$-cell function was assessed by reference to the plasma insulin concentration achieved in the last 20 min of a $2.5-\mathrm{h}$ hyperglycaemic clamp, expressed as percent of the median of the values $(33 \mathrm{mU} / \mathrm{l})$ for normal weight, normal subjects
[9]. Insulin resistance was assessed by the glucose clearance relative to achieved plasma insulin [9], expressed as a ratio to the median of values for normal subjects: $0.18 \times$ [mean plasma insulin $\left.\mathrm{mU} \cdot \mathrm{1}^{-1}\right] /[\mathrm{mg}$ glucose infused $/ \mathrm{kg}$ body weight per min]. HOMA was assessed from the $15 \mathrm{~min}$ 'stressed fasting' samples before the hyperglycaemic clamp.

Reproducibility studies. Nine normal subjects (aged 22-29years, 96-107\% ideal body weight), and nine Type 2 diabetic subjects on diet only (aged $46-68$ years, $106-188 \%$ ideal body weight) were studied with a CIGMA on two separate occasions within 3 weeks. Clinical details of the diabetic patients are given in Table 1.

HOMA was performed on two separate occasions in each of the 11 diabetic and 10 normal subjects who attended from home on one morning for a hyperglycaemic clamp and on another for CIGMA. On both occasions, the HOMA was based on observations during the last $15 \mathrm{~min}$ of the 30 -min pre-infusion sampling period.

\section{Laboratory analyses}

Plasma insulin and glucose assays have been described previously [9] The values for different tests were measured in separate assays.

The erythrocyte separation and monocyte receptor assays were carried out using a modified method of Gambhir et al. [15] previously described [16]. The monocytes were checked for viability using Trypan Blue (for all suspensions viability $>95 \%$ ). Monocytes were identified by non-specific esterase staining. The percentage of monocytes ranged from $12 \%$ to $28 \%$, the other cells being almost exclusively lymphocytes identified by Leishman's stain. The same mono-iodinated ${ }^{125} \mathrm{I}$ [A-14] insulin was used on each of the occasions for each subject.

\section{Selection of samples for HOMA}

In general, the fasting plasma glucose and insulin observations used for HOMA were obtained on the same day as the independent clamp or intravenous glucose tolerance tests with which the HOMA results were compared. On euglycaemic clamp days, a single fasting plasma samples was used, but otherwise the 'fasting' plasma insulin and glucose concentrations were the means of the results on the last 15 of 30 samples taken at 1 -min intervals before the test. This period was chosen in view of the 14-min cycles of plasma insulin secretion known to occur in normal man [17].

\section{Statistical methods}

Correlations were assessed by a non-parametric test (Spearman, $R_{\mathrm{s}}$ ). Coefficient of variation was assessed by the formula for duplicates:

$$
\frac{\sqrt{\frac{\Sigma(\text { difference })^{2}}{2 n}}}{\text { mean }}
$$




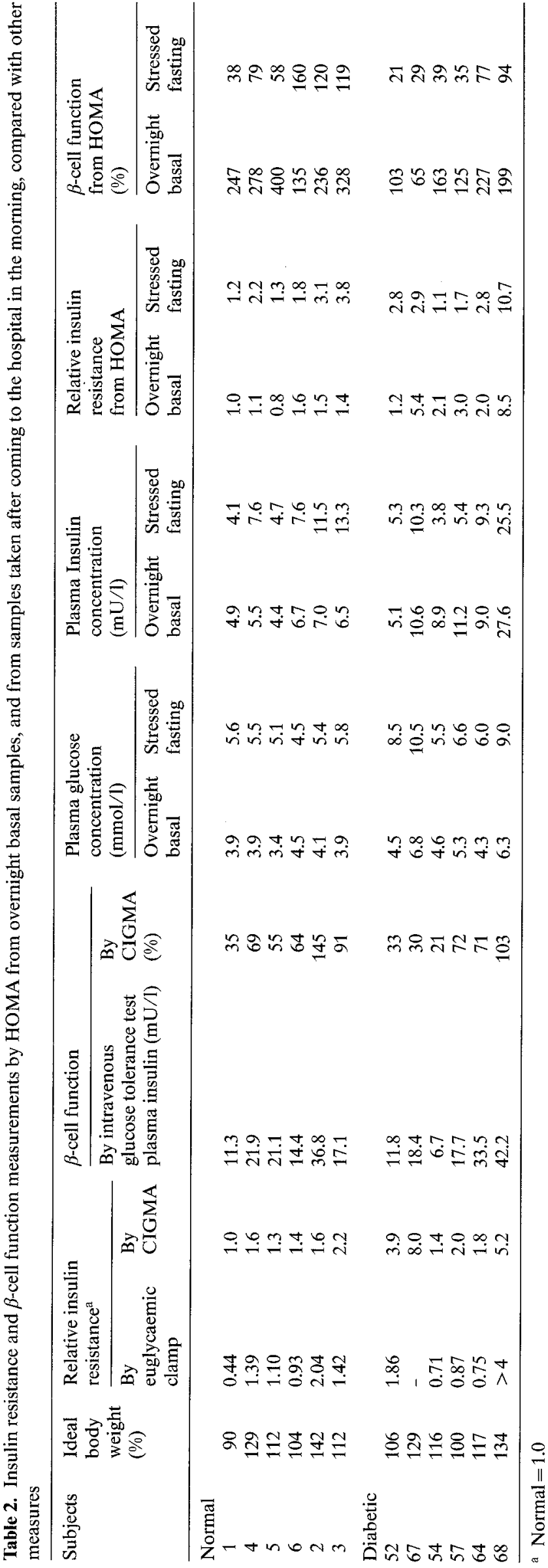

\section{Results}

Comparisons of methods of assessing insulin resistance

HOMA compared with the euglycaemic hyperinsulinaemic clamp. The HOMA estimate of insulin resistance correlated with that measured by the euglycaemic clamp in the 12 normal subjects $\left(\mathrm{R}_{\mathrm{s}}=0.83, p<0.01\right)$, in the 11 diabetic subjects $\left(\mathrm{R}_{\mathrm{s}}=0.92, p<0.0001\right)$ and in both groups together $\left(\mathrm{R}_{\mathrm{s}} 0.88, p<0.0001\right.$; Fig. 2$)$. The median insulin resistance in normal subjects was 1.21 as assessed by HOMA and 1.45 by euglycaemic clamp, while in diabetic subjects it was 2.89 by HOMA and 4.1 by euglycaemic clamp. The single 'stressed fasting' plasma insulin values alone gave similar correlations with the euglycaemic clamp estimate of resistance $\left(R_{\mathrm{s}}=0.81\right.$, $p<0.0001)$ and with the estimate by HOMA $\left(\mathrm{R}_{\mathrm{s}}=0.93\right.$, $p<0.0001)$.

HOMA compared with the hyperglycaemic clamp. The HOMA estimate of insulin resistance from the mean of 15 'stressed fasting' samples before the clamp correlated with that measured by the hyperglycaemic clamp in the 10 normal subjects $\left(\mathrm{R}_{\mathrm{s}}=0.55, p<0.1\right)$, in the 11 diabetic subjects $\left(\mathrm{R}_{\mathrm{s}} 0.68, p=0.02\right)$ and in both groups together $\left(\mathrm{R}_{\mathrm{s}}=0.69, p=0.0005\right.$, Fig. 2$)$. The median insulin resistance for normal subjects was 1.45 as assessed by HOMA and 0.97 by hyperglycaemic clamp; for diabetic subjects it was 2.61 by HOMA and 1.1 by the clamp.

HOMA compared with CIGMA. The HOMA estimate of insulin resistance from the mean of 15 stressed fasting samples before the CIGMA correlated with that measured by CIGMA in 11 normal subjects $\left(R_{s}=0.69\right.$, $p<0.02)$, in 12 diabetic subjects $\left(\mathrm{R}_{\mathrm{s}} 0.97, p<0.0001\right)$ and in both groups together $\left(\mathrm{R}_{\mathrm{s}}=0.87, p<0.0001\right)$. The median resistance for normal subjects was 1.21 by HOMA and 1.35 by CIGMA, and for the diabetic subjects 2.89 by HOMA and 3.9 by CIGMA.

Comparisons with monocyte and erythrocyte insulin receptor binding data. The insulin receptor binding data from erythrocytes and monocytes were analysed in terms of insulin binding with no added insulin and binding at increasing concentrations of insulin. The data were analysed by both Scatchard and negative cooperativity theories. Neither receptor numbers or any aspect of high or low affinity binding correlated with other measures of insulin resistance (HOMA, clamp, basal insulin or CIGMA: $\mathrm{R}_{\mathrm{s}}$ all $<0.55$; NS).

\section{Reproducibility of estimates of insulin resistance by HOMA}

The coefficient of variation of the HOMA estimates of resistance was $40 \%$ from the 2 days on which the nine normal subjects had repeat glucose infusions, $30 \%$ for the corresponding values in the nine diabetic subjects, and $34 \%$ for all subjects combined. 


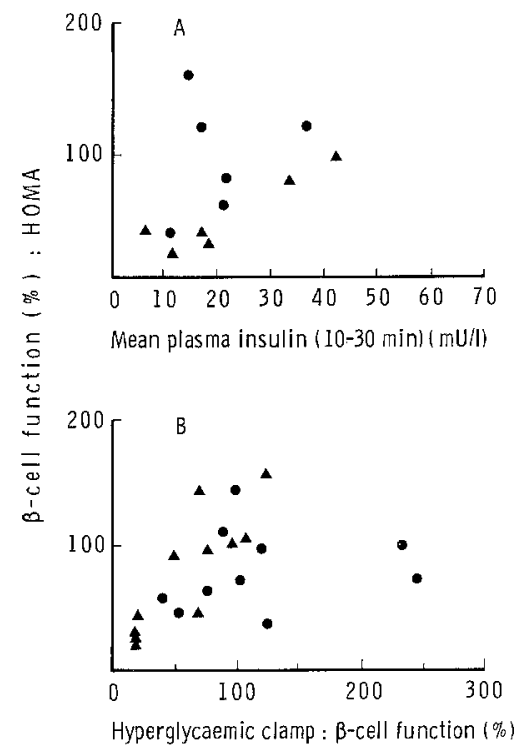

Fig.3A and B. Relative measures of $\beta$-cell function by HOMA compared with those assessed by: $\mathbf{A}$ intravenous tolerance test in six normal ( $\bullet$ ) and five diabetic ( $\mathbf{A}$ ) subjects; $\mathbf{B}$ hyperglycaemic clamp in a different group of normal (O) and diabetic ( $\mathbf{\Delta})$ subjects. $\beta$-cell function from an intravenous glucose tolerance test is expressed as the mean plasma insulin between 10 and $30 \mathrm{~min}$ after the glucose bolus. The $\beta$-cell function from the $10 \mathrm{mmol} / 1$ hyperglycaemic clamp has been normalised to $100 \%$ for the median plasma insulin concentration attained by normal weight, normal subjects [9]

Measures of insulin resistance

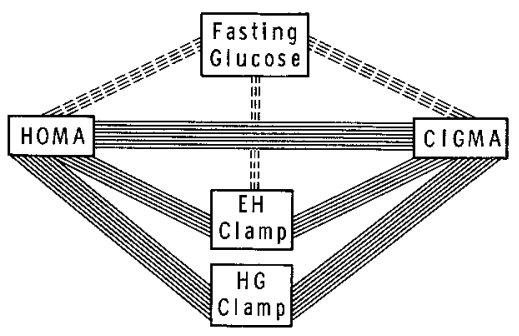

Measures of $\beta$-cell function

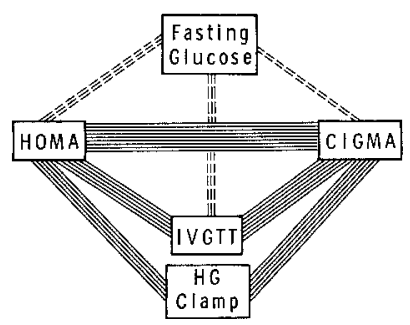

Fig.4. A graphical summary of the correlations between the tests used to estimate $\beta$-cell function (upper panel) and insulin resistance (lower panel) from the six normal and six diabetic subjects studied on three occasions. HOMA = homeostasis model assessment; CIG$\mathrm{MA}=$ continuous infusion of glucose with model assessment; $\mathrm{EH}$ Clamp = euglycaemic hyperinsulinaemic clamp; HG clamp = hyperglycaemic clamp; IVGTT = intravenous glucose tolerance test. The hyperglycaemic clamp data are from 10 normal and 11 diabetic subjects. Each line represents a Spearman rank correlation coefficient of 0.1 units (thus 5 lines indicate $\mathrm{R}_{\mathrm{s}}=0.5$ ); $-=p<0.05$, ----- $=p>0.05$
The coefficient of variation of the HOMA estimates of resistance on the 2 days that the 11 diabetic and 10 normal subjects had CIGMA and hyperglycaemic clamps, was $32 \%$ in normal subjects, $23 \%$ in diabetic subjects, and $27 \%$ overall. The mean coefficient of variation over the two studies was $31 \%$.

\section{Insulin resistance assessed from a single sample or three samples over $10 \mathrm{~min}$}

The data from the samples were analysed to establish whether observations on a single 'stressed fasting' sample, or the means of observations on samples taken over $15 \mathrm{~min}$, were better for HOMA analysis. The results from the six normal and six diabetic subjects who were studied on three separate occasions were analysed (Table 2). HOMA estimates of insulin resistance from the single 'stressed fasting' sample before the euglycaemic clamp correlated better with the euglycaemic clamp estimate of resistance on the same day $\left(\mathrm{R}_{\mathrm{s}} 0.77, p<\right.$ $0.005)$ than did the values from the mean of the 15 -min values (on a different day) before the CIGMA $\left(R_{s} 0.62\right.$, $p<0.04)$. The median HOMA values for the normal subjects on the single sample and 15-min samples were 1.96 and 1.35 , respectively, and those for diabetic subjects were 2.42 and 2.39 , respectively. Not all $15-\mathrm{min}$ samples needed to be analysed: the resistance estimate by HOMA using the mean of results of three samples at 0,5 and $10 \mathrm{~min}$ was correlated with the estimate from HOMA using the mean of results on 15 consecutive 1 -min samples $\left(\mathrm{R}_{\mathrm{s}} 0.98, p<0.0001\right)$, and accordingly was also correlated with resistance estimated by euglycaemic clamp $\left(\mathrm{R}_{\mathrm{s}} 0.70, p<0.021\right)$.

Similar comparisons of sampling were done with the 15 consecutive 1-min samples before the CIGMA infusion in the 12 diabetic and 11 normal subjects who had an euglycaemic clamp. The resistance values from the mean of results from the 15 consecutive 1-min samples and from the mean of results from samples at times 0,5 and $10 \mathrm{~min}$ were correlated with the euglycaemic clamp resistance estimates $\left(R_{\mathrm{s}}=0.89\right.$ and 0.88 respectively; $p<0.0001$ ).

In the study of repeat glucose infusions in nine normal and nine diabetic subjects, the coefficient of variation was similar whether mean results from multiple samples $(34 \%)$ or single plasma samples $(30 \%)$ were used.

Insulin resistance assessed from 'overnight basal' samples or from 'stressed fasting' samples

Insulin resistance by HOMA from 'overnight basal' $(03.00-05.00 \mathrm{~h})$ samples in the six normal and six diabetic subjects correlated with the 'basal' $(06.30-07.30 \mathrm{~h})$ value on the same day $\left(\mathrm{R}_{\mathrm{s}}=0.90, p<0.0001\right.$, Table 2$)$, and with the HOMA results on the mean observations from 'stressed fasting' samples 0,5 and $10 \mathrm{~min}$ before the CIGMA test on a different day $\left(\mathrm{R}_{\mathrm{s}} 0.70, p=0.011\right)$. 
There was no quantitative difference between the overnight basal samples and the morning basal values in respect of the insulin resistance measured by HOMA (medians: normal subjects $1.3,2.0$ respectively, diabetic subjects $2.5,2.8$, respectively). These values were similar to those obtained by HOMA on the euglycaemic clamp day (median: normal subjects 1.96, diabetic subjects 2.4).

\section{Comparisons of methods of assessing $\beta$-cell function}

HOMA compared with hyperglycaemic clamp. The HOMA estimate of $\beta$-cell function assessed from a $15-\mathrm{min}$ period of sampling correlated with that measured by the hyperglycaemic clamp in 10 normal subjects alone $\left(\mathrm{R}_{\mathrm{s}}=0.59, p<0.05\right)$, in 11 diabetic subjects alone $\left(\mathrm{R}_{\mathrm{s}}=0.71, p<0.02\right)$ and in both groups together $\left(\mathrm{R}_{\mathrm{s}}\right.$ $0.61, p<0.01$ : Fig. 3). The median $\beta$-cell function values were $115 \%$ by HOMA and $100 \%$ by hyperglycaemic clamp for normal subjects, and $80 \%$ by HOMA and $69 \%$ by hyperglycaemic clamp for diabetic subjects.

HOMA compared with intravenous glucose tolerance test. $\beta$-cell function assessed from the plasma insulin levels during the intravenous glucose tolerance test correlated with the HOMA estimates of $\beta$-cell function assessed from the basal period on the same day (in normal subjects: $R_{\mathrm{s}}=0.54, \mathrm{NS}$; in diabetic subjects: $\mathrm{R}_{\mathrm{s}}=0.77, p<$ 0.01 ; and in both groups together: $\mathrm{R}_{s}=0.64, p<0.05$; Fig. 3). The median values of the estimates of $\beta$-cell function by HOMA for normal and diabetic subjects were $101 \%$ and $45 \%$, respectively.

HOMA compared with CIGMA. The CIGMA estimates of $\beta$-cell function correlated significantly with the HOMA estimates from samples taken over a 15 -min period on the same day in normal subjects $\left(\mathrm{R}_{\mathrm{s}}=0.73, p<0.01\right)$, in diabetic subjects $\left(\mathrm{R}_{\mathrm{s}}=0.7, p<0.01\right)$ and in both groups of subjects together $\left(\mathrm{R}_{\mathrm{s}}=0.90, p<0.0001\right)$. The median values for $\beta$-cell function were $113 \%$ by HOMA and $92 \%$ by CIGMA in normal subjects and $68 \%$ by HOMA and $52 \%$ by CIGMA in diabetic subjects.

\section{Reproducibility of estimate of $\beta$-cell function by HOMA}

The coefficients of variation of the paired estimates of $\beta$-cell function by HOMA performed before glucose infusions were $38 \%$ in nine normal subjects, $33 \%$ in nine diabetic subjects, and $35 \%$ in all subjects.

The coefficients of variation of the paired estimates of $\beta$-cell function by HOMA performed before CIGMA and hyperglycaemic clamps were $30 \%$ in normal subjects, $27 \%$ in diabetic subjects and $29 \%$ in all subjects. The mean coefficient of variation over the two studies was $32 \%$.

\section{$\beta$-cell function assessed from either a single sample or three samples over $10 \mathrm{~min}$}

The data from the samples were analysed to establish whether a single 'stressed fasting' observation or the mean of data taken over $15 \mathrm{~min}$ was better for HOMA analysis. The results from the 10 normal and 11 diabetic subjects who had a hyperglycaemic clamp were analysed. The HOMA estimate of $\beta$-cell function from the single "stressed fasting' sample before the hyperglycaemic clamp correlated with the corresponding clamp estimate of $\beta$-cell function, whether a single sample $\left(\mathrm{R}_{\mathrm{s}}\right.$ $0.57, p=0.007$ ) or whether the values from the mean of the 15 consecutive 1-min values on the same day were used $\left(\mathrm{R}_{\mathrm{s}} 0.61, p=0.003\right)$. The median values based on the single sample in the normal and the diabetic subjects were $115 \%$ and $80 \%$, respectively.

In the study of repeat glucose infusions in nine normal and nine diabetic subjects, the coefficient of variation between the HOMA estimates of $\beta$-cell function was smaller when using the mean of 0,5 and $10-\mathrm{min}$ samples to estimate function (coefficient of variation $35 \%$ ) than when using 'stressed fasting' samples (coefficient of variation $52 \%$ ).

\section{$\beta$-cell function assessed from overnight basal 'samples' or from 'stressed fasting samples'}

HOMA estimates of $\beta$-cell function from 'overnight basal' (03.00-05.00 hours) samples in the six normal and six diabetic subjects correlated with those from the 'basal' $(06.30-07.30 \mathrm{~h})$ samples on the same day $\left(\mathrm{R}_{\mathrm{s}}=0.78, p=0.026\right.$, Table 2$)$, and with those from the mean 0,5 and $10 \mathrm{~min}$ 'stressed fasting' results before the CIGMA test on the different day $\left(\mathrm{R}_{\mathrm{s}} 0.64, p=0.026\right)$.

Median values of the HOMA estimates from 'overnight basal' and 'morning basal' samples were, respectively, $150 \%$ and $162 \%$ in normal, and $117 \%$ and $101 \%$ in diabetic subjects. These values differed quantitatively from those obtained using 'stressed fasting' samples before intravenous glucose tolerance test $(101 \%$ in normal and $45 \%$ in diabetic subjects).

\section{Discussion}

The simplest aspect of the glucose and insulin homeostatic feed-back loop is in the basal state [18]. The basal hyperglycaemia of diabetes may be considered as a compensatory response with a major rôle in maintaining sufficient insulin secretion, from a reduced $\beta$-cell capacity, to control hepatic glucose efflux $[1,4]$. We have investigated this with a model of the interactions between insulin and glucose, based on available data on $\beta$ cell, hepatic and peripheral responses $[5,6,9]$. For any combination of insulin resistance and $\beta$-cell function, the model predicts unique values for basal glucose and insulin concentrations. The whole array may be repre- 
sented graphically (Fig. 1); observations from an individual patient can be plotted and the predicted values for insulin resistance and $\beta$-cell function may be obtained from the graph.

This use of modelling to provide a reference graph contrasts with other models where an individual patient's data have to be entered into a computer to determine the relationships between rapidly changing variables, such as occur after an intravenous glucose test [19].

In principle, the HOMA of fasting insulin and glucose levels should be able to differentiate $\beta$-cell deficit from insulin resistance without any of the problems of using an artificial stimulus. In practice, however, the estimation of the set of a patient's feed-back loop from fasting insulin values by HOMA is unlikely to be precise. The range over which insulin is measured is small and the results depend on the precision of the insulin radioimmunoassay. The pulsatility of insulin secretion [17], uncertainty whether proinsulin is being measured as insulin [20], and the effects of stress [2] or exercise [21] could affect interpretation of assay results.

The fasting insulin concentration and HOMA assessment of insulin resistance correlated with other estimates of insulin resistance. This is not surprising in view of the manner in which the feed-back loop is bound to increase the basal plasma insulin level to overcome hepatic insulin resistance $[5,6]$. In this study, the assessment by HOMA correlated with the resistance assessed by fasting plasma insulin alone, but the diabetic patients studied did not have marked hyperglycaemia and Figure 1 shows, under these circumstances, that the insulin concentration is a simple function of insulin resistance.

Overnight basal plasma glucose concentrations are slightly lower than on stressed fasting samples when the patient has been up [2]. HOMA provides reasonable estimates of insulin resistance in all fasting samples, but better estimates of $\beta$-cell function on stressed fasting than overnight basal samples. HOMA assessment of $\beta$ cell function is not as good for normal as for diabetic subjects, partly because of the proximity of different $\beta$ cell function lines at normal glucose concentrations (Fig.1) and partly because younger normal subjects have a sigmoid rather than the linear $\beta$-cell steady-state glucose: C-peptide response curve used in the model [11]. In addition, the basal plasma glucose concentration in normal subjects depends on the 'set' of the sensitivity of their $\beta$-cells at slightly different fasting plasma glucose concentrations rather than on quantitative differences in maximal $\beta$-cell function [21]. Nevertheless, HOMA results correlate with other measures of $\beta$-cell function and insulin resistance, and a graphical summary of correlations between different measures is shown in Figure 4. The degree of the hyperglycaemia does not correlate significantly with either the degrees of abnormal $\beta$-cell function or insulin resistance. This is not surprising in that the hyperglycaemia results from a combination of these two factors, rather than from either alone.

It is necessary to measure the fasting plasma insulin over a 15 -min period, in subjects who are rested, to avoid the confounding effects of oscillatory release [17] and stress [2]. A single fasting sample taken in the outpatient clinic is unlikely to be a reliable guide to a subject's insulin resistance or $\beta$-cell function. If HOMA is undertaken, there are advantages in precision to be gained from sampling at three separate intervals $5 \mathrm{~min}$ apart. Even then, the high coefficient of variation of measurement of either $\beta$-cell function or insulin resistance on different days (30\%), makes HOMA less reliable than CIGMA. One advantage of CIGMA is that the infused glucose "expands the scale" over which the same homeostatic responses occur, and thus enables more precise assessment.

Although the imprecision limits the clinical application of HOMA estimates from a single blood sample, the significant correlations of HOMA estimates with independent measurements of $\beta$-cell function and insulin resistance support the theoretical background of the analysis. Thus, the fasting plasma insulin and glucose concentrations found in normal and diabetic subjects were similar to those which the mathematical model predicted, given the insulin resistance and $\beta$-cell function as measured by other tests. Whilst this does not exclude many factors having an influence on the basal concentrations it accords with a major rôle for the simple interaction of plasma glucose and insulin between the liver, $\beta$-cells and periphery.

Acknowledgements. We are grateful to the Charles Wolfson Charitable Trust, to Bayer UK Ltd. and the Oxford Medical School Research Fund for grants; to Mrs. E. Harris, Mrs. M. Burnett, Mrs. P. Darling and Mr. R. Pinches for their skilled technical help, and to Miss R. Church for secretarial support. Dr. D. R. Matthews is the Joan and Richard Doll Senior Research Fellow at Green College, and Dr. A.S. Rudenski has a MRC Training Fellowship.

\section{References}

1. Holman RR, Turner RC (1979) Maintenance of basal plasma glucose and insulin concentration in maturity-onset diabetes. Diabetes $28: 227-230$

2. Holman RR, Turner RC (1980) The basal plasma glucose: a simple relevant index of maturity onset diabetes. Clin Endocrinol 14: 279-286

3. McCarthy ST, Harris F, Turner RC (1977) Glucose control of basal insulin secretion in diabetes. Diabetologia 13: 93-97

4. Turner RC, Holman RR (1976) Insulin rather than glucose homeostasis in the pathophysiology of diabetes. Lancet 1: 1272-1274

5. Turner RC, Holman RR, Matthews DR, Hockaday TDR, Peto J (1979) Insulin deficiency and insulin resistance interaction in diabetes: estimation of their relative contribution by feedback analy. sis from basal insulin and glucose concentrations. Metabolism 28: 1086-1096

6. Turner RC, Matthews DR, Holman RR, Peto J (1982) Relative contributions of insulin deficiency and insulin resistance in maturity-onset diabetes. Lancet: 596-598 
7. DeFronzo RA, Tobin JD, Andres R (1979) Glucose clamp technique: a method for quantifying insulin secretion and resistance. Am J Physiol 237: E214-223

8. Olefsky JM (1979) The insulin receptor: its role in insulin resistance of obesity and diabetes. Diabetes 25: 1154-1161

9. Hosker JP, Matthews DR, Rudenski AS, Burnett MA, Darling P, Bown EG, Turner RC (1985) Continuous infusion of glucose with model assessment: measurement of insulin resistance and beta cell function in man. Diabetologia 28: 401-411

10. World Health Organisation (1980) Expert Committee on Diabetes Mellitus. Technical Report Series 646. WHO, Geneva

11. Hosker JP, Burnett MA, Davies EG, Matthews DR, Rudenski AS, Turner RC (1984) Loss of normal sigmoidal beta cell response curve to glucose in non-insulin-dependent diabetes. Diabetologia 27: $289 \mathrm{~A}$

12. Ellis BW, Randall NJ, Becket AJ, Dudley HAF (1976) Continuous blood sampling and time series analysis. J Med Eng Technol 2: 195-199

13. Metropolitan Life Assurance Co (1959) Net weight standard for men and women. Stat Bull Metrol Life Found 40:1-4

14. Matthews DR, Hosker JP (1984) An unbiased, flexible computer programme for glucose clamping, with graphics and running statistics. Diabetologia 27:308-309 A

15. Gambhir KK, Archer JA, Bradley CJ (1972) Characteristics of human erythrocyte insulin receptors. Diabetes 27: 701-708

16. Matthews DR, Naylor BA, Jones RG, Ward GM, Turner RC (1983) Pulsatile insulin secretion has a greater hypoglycaemic effect than continuous delivery. Diabetes 32:617-621
17. Matthews DR, Lang DA, Burnett MA, Turner RC (1983) Control of pulsatile insulin secretion in man. Diabetologia 24: 231-237

18. Turner RC, Matthews DR (1984) Insulin secretion in Type I and Type 2 diabetes. Front Diabetes 4: 36 54

19. Bergman RN, Ider YZ, Bowden CR, Cobelli C (1979) Quantitative estimation of insulin sensitivity. Am J Physiol 236: E667-E677

20. Rubenstein A, Robbins D, Tager H, Blix P, Berganstal R, Given B, Kanazawa $Y$ (1982) Clinical significance of circulating proinsulin and C-peptide In: Skyler JS (ed) Insulin update. Excerpta Medica, London, Amsterdam, pp 24-40

21. LeBlanc J, Tremblay A, Richard D, Nadeau A (1983) Daily variations of plasma glucose and insulin in physically trained and sedentary subjects. Metabolism 32: 552-557

22. Turner RC, Harris EA, Ounstead M, Ponsford C (1979) Two abnormalities of glucose-induced insulin secretion: dose-response characteristics and insulin sensitivity. Acta Endocrinol 92: 148-165

Received: 15 December 1983

and in revised form: 31 May 1985

Dr. R.C.Turner

Diabetes Research Laboratories

Radcliffe Infirmary

Woodstock Road

Oxford

UK 